\title{
Las vacunas en la práctica médica actual
}

\section{Vaccines in current medical practice}

\author{
Roberto SÁnchez-Ramírez* \\ 'Dirección General de Coordinación de los Hospitales Regionales de Alta Especialidad, Comisión Coordinadora de institutos Nacionales y Hospitales de Alta \\ Especialidad, Ciudad de México, México
}

La información durante la pandemia causada por el SARS-CoV-2 oscila del horror a la esperanza. Del miedo cerval provocado por la frecuencia y distribución de casos y defunciones, a la exigencia mundial que acelera la creación de las vacunas que contribuyan al control de esta nueva enfermedad infecciosa.

Del lado de la esperanza, la exigencia está justificada con base en el conocimiento y experiencia de más 200 años (Edward Jenner, 1796) en el uso preventivo de las vacunas. Así, se ha logrado erradicar del mundo a la viruela en 1980, casi eliminar la poliomielitis (Jonas Salk, y Albert Sabin), disminuir de manera importante los casos de rabia humana (Louis Pasteur) y difteria (von Behring, 1923), además de la disminución en la incidencia de la tuberculosis (Calmette y Guérin), rubéola y sarampión

Con tal bagaje y a pesar de la premura, se vaticina que las anheladas vacunas cumplirán con las normas y estándares internacionales de calidad y seguridad para productos biológicos que, aplicadas en campañas masivas, reducirán en un alto porcentaje de la población el riesgo de contraer la enfermedad, interrumpirán la transmisión del virus SARS-CoV2 y estimularán el ánimo mundial.

Mientras la proeza se cumple, antes de entonar cantos de victoria, aún es tiempo de reflexionar fuera de los límites de la fracción de realidad que abarcan las ciencias biomédicas y clínicas e incorporar al análisis de la magnitud y trascendencia la determinación social de la enfermedad y la función de las vacunas en la sociedad.

Con ello se pretende desdeñar la promesa farmacológica de superar la pandemia hasta la gestación de la «bala mágica» (producto con toxicidad selectiva para los microorganismos; Paul Ehrlich, 1902), ya desestimada en la actual crisis sanitaria por el director de la Organización Mundial de la Salud (OMS). Asimismo, descalificar el discurso del movimiento social antivacunas, que encontró argumentos en publicaciones de investigadores clínicos que actuaron de forma deshonesta e irresponsable y que, ahora, volverá a la plaza empleando las redes sociales digitales para minar la credibilidad y aceptación de las vacunas desarrolladas y autorizadas de emergencia para su uso, atribuyendo la presencia de posibles efectos adversos a la reducción del tiempo de producción y relajar el rigor de normas y estándares; todo ello en un contexto de tensión geopolítica que se intensificará principalmente por la competencia comercial para dominar el mercado.

En estricto sentido, las vacunas son productos biológicos (suspensión de microorganismos muertos o atenuados, o de productos o derivados de microorganismos, incluyendo actualmente de material genético) destinados a generar inmunidad contra una enfermedad estimulando en el individuo la producción de anticuerpos. Mediante las campañas de aplicación masiva han devenido en la medida sanitaria mejor costo/efectiva para el control de algunas enfermedades infecciosas,

\section{Correspondence:}

${ }^{*}$ Roberto Sánchez-Ramírez

E-mail: rsr5205@ hotmail.com
Date of reception: 28-04-2021

Date of acceptance: 29-04-2021

DOI: 10.24875/HMCM.M21000014
Available online: 25-06-2021

Hosp Med Clin Manag. 2020;13:141-2

2604-0018 / ( 2021 Mexican Regional Hospitals of High Specialty and Federal Hospitals. Published by Permanyer. This is an open access article under the CC BY-NC-ND license (http://creativecommons.org/licenses/by-nc-nd/4.0/). 
particularmente en aquellos países no desarrollados, en donde la desigualdad social se manifiesta con profundas carencias en las condiciones materiales de vida y deficientes e insuficientes servicios públicos.

Desafortunadamente, los logros conseguidos con las vacunas han producido la falsa percepción de evitar por sí solas las enfermedades infecciosas en la sociedad, sin atender a sus determinantes estructurales.

Las vacunas nunca tendrán tal capacidad. No obstante, el sistema económico dominante las ha incorporado a su visión de progreso y las oferta con envoltura de bienestar, mientras que el porcentaje de la población en pobreza continúa acumulándose y, por supuesto, alimentando el caldo de cultivo para enfermedades, claro, prevenibles por vacunación.

Enfrentar con la mercantilización de productos biológicos los determinantes sociales de la enfermedad, es uno de los elementos del proceso ideológico que se ha ido constituyendo de forma progresiva en el pensamiento y práctica social de la medicina contemporánea desde la segunda mitad del siglo xix, cuando ante el flagelo de la tuberculosis, se eligió la adopción de la perspectiva biológica (postulados de Roberto Koch) y desarrollar con enfoque curativo la medicina interna, antes que la medicina social (Rodolfo Virchow).
Esta primera versión del modelo imperante en la medicina contemporánea pronto mostró su ineficacia, dando paso a la dimensión psicológica y social en el concepto de salud, así como reformas en la organización y función de la atención médica, planteadas por la OMS desde la segunda mitad del siglo xx .

Pero ello no significó que se hayan concretado en los hechos; en cambio, la orientación de dicho modelo, enclaustrado en el hospital, separó al individuo de su familia, lo fraccionó en órganos y funciones para desembocar en la medicina curativa, especializada y distanciada de las necesidades reales de salud. El concepto integral del individuo, la promoción de la salud y la medicina general y preventiva del primer nivel de atención debían esperar.

Hoy, con la pandemia en curso, este modelo de medicina enfrenta nuevamente su propia némesis con la promesa de que la vacuna será el alivio a la crisis global.

No se cuenta con otra alternativa y desde ahora se sabe que no será perfecta, por lo que su eficacia biológica deberá ser complementada con la reorientación de la práctica médica y de los servicios públicos de salud. Corresponderá a la sociedad organizada potenciar el beneficio de la vacuna con acciones tendientes a mejorar sus propias condiciones de trabajo y vida. 